\title{
Treatment of the young active patient with osteoarthritis of the hip
}

\author{
A FIVE- TO SEVEN-YEAR COMPARISON OF HYBRID TOTAL HIP \\ ARTHROPLASTY AND METAL-ON-METAL RESURFACING
}

T. C. B. Pollard, R. P. Baker, S. J. EastaughWaring, G. C. Bannister

From the Avon Orthopaedic Centre and BUPA Glen Hospital, Bristol, England

T. C. B. Pollard, BSc(Hons), MBChB, MRCS, Specialist Registrar in Orthopaedics Wycombe Hospital, Queen Alexandra Road, High Wycombe, Buckinghamshire HP11 2TT, UK.

- R. P. Baker, MBChB, MRCS, Specialist Registrar in Orthopaedics

S. J. Eastaugh-Waring, MBChB, FRCS(Tr \& Orth), Consultant Orthopaedic Surgeon

G. C. Bannister, MD, FRCS Consultant Orthopaedic Surgeon

Avon Orthopaedic Centre, Southmead Hospital, Bristol, BS10 5NB, UK.

Correspondence should be sent to Mr G. C. Bannister; e-mail: gordon.bannister@nbt.nhs.uk

(C)2006 British Editorial Society of Bone and Joint Surgery doi:10.1302/0301-620X.88B5. $17354 \$ 2.00$

$J$ Bone Joint Surg $[\mathrm{Br}]$ 2006;88-B:592-600. Received 27 October 2005 Accepted after revision 19 January 2006

\begin{abstract}
We compared the five- to seven-year clinical and radiological results of the metal-on-metal Birmingham hip resurfacing with a hybrid total hip arthroplasty in two groups of $\mathbf{5 4}$ hips, matched for gender, age, body mass index and activity level.

Function was excellent in both groups, as measured by the Oxford hip score, but the Birmingham hip resurfacings had higher University of California at Los Angeles activity scores and better EuroQol quality of life scores. The total hip arthroplasties had a revision or intention-to-revise rate of $8 \%$, and the Birmingham hip resurfacings of $6 \%$. Both groups demonstrated impending failure on surrogate end-points. Of the total hip arthroplasties, $12 \%$ had polyethylene wear and osteolysis under observation, and $8 \%$ of Birmingham hip resurfacings showed migration of the femoral component. Polyethylene wear was present in $\mathbf{4 8} \%$ of the hybrid hips without osteolysis. Of the femoral components in the Birmingham hip resurfacing group which had not migrated, $66 \%$ had radiological changes of unknown significance.
\end{abstract}

Premature failure of cemented total hip arthroplasty (THA) in active men under 50 years of age is predominantly because of aseptic loosening of the acetabular component. ${ }^{1-5}$ As a result, porous-coated, uncemented, metal hemispherical acetabular components with press-fit polyethylene liners were introduced, combined with a cemented stem as the "hybrid hip ${ }^{9,7}$ and were widely used, particularly in younger patients. Femoral bone-conserving metal-onmetal hip resurfacing was introduced in the early $1990 \mathrm{~s},{ }^{8,9}$ but the results have been reported largely from the inventing centres ${ }^{10-12}$ with follow-up periods of less than five years. ${ }^{13-15}$

The aim of this study was to compare the functional results, failure rates and impending revisions in hybrid THAs and Birmingham hip resurfacing in young active patients.

\section{Patients and Methods}

This study compared 54 of the first 63 metalon-metal Birmingham hip resurfacings performed by the senior author (GCB) with 54 hybrid THAs reviewed retrospectively in patients matched for gender, age, body mass index (BMI) and activity level. We previously reported very early clinical results. ${ }^{15}$

Original study groups. Between January 1996 and April 2001, 54 hips in 53 patients (13 women/13 hips and 40 men/41 hips) under- went hybrid THA using the cemented CPT stem (Zimmer, Warsaw, Indiana), with an uncemented acetabular component and a press-fit polyethylene liner. The uncemented acetabular components included 29 HarrisGalante II (Zimmer), 16 ABG II (Stryker Orthopedics, Mahwah, New Jersey), seven Zweymuller (PLUS Orthopedics, Rotkreuz, Switzerland), one PFC (DePuy International, Leeds, United Kingdom) and one Hedrocel (Implex Corp, Allendale, New Jersey). In 45 hips a $28 \mathrm{~mm}$ modular metal femoral head was used and in nine, a ceramic head.

Between August 1999 and April 2001, 63 hips were resurfaced using the Birmingham hip resurfacing (Midland Medical Technologies, Birmingham, United Kingdom). This comprised a cemented femoral component and an uncemented hemispherical flanged hydroxyapatite- and porous-coated acetabular component. On no occasion during this period did the senior author (GCB) decide intra-operatively that a case was unsuitable for resurfacing and perform a THA instead. Of the 63 hips, three were revised for fracture of the femoral neck (two within six weeks of implantation and the other at one year because of avascular necrosis). They were included in the results as failures but excluded from further follow-up. There were six hips not available for followup, leaving 54 surviving Birmingham hip resur- 
Table I. Summary of pre-operative diagnoses

\begin{tabular}{lll}
\hline \multirow{2}{*}{ Pathology } & \multicolumn{2}{l}{ Number of hips (\%) } \\
\cline { 2 - 3 } \cline { 2 - 3 } & Hybrid group & Resurfacing group \\
\hline Osteoarthritis & $40(74)$ & $42(78)$ \\
Avascular necrosis & $7(13)$ & $4(7)$ \\
Developmental dysplasia & $3(6)$ & $3(6)$ \\
Rheumatoid arthritis & $1(1)$ & $0(0)$ \\
Others $^{*}$ & $3(6)$ & $5(9)$ \\
\hline
\end{tabular}

* slipped capital femoral epiphysis; Perthes' disease; ankylosing spondylitis; post-traumatic osteoarthritis

facings in 51 patients (11 women/13 hips and 40 men/41 hips).

The patients having hybrid THAs were matched with those having Birmingham hip resurfacings for gender, age at surgery (within five years), BMI (within $5 \mathrm{~kg} / \mathrm{m}^{2}$ ) and pre-operative activity level before it was limited by symptoms. Activity was graded using the University of California at Los Angeles (UCLA) activity score, ${ }^{16-18}$ which ranges from one point (inactive) to ten points (regular impact sport). We matched patients within two points on the scale. The mean age of the hybrid THA patients was 50.4 years (21 to 66$)$, mean BMI was $27.0 \mathrm{~kg} / \mathrm{m}^{2}$ (18.5 to 37.0$)$ and the mean pre-operative activity level was 8.9 points (6 to 10). The mean age for the Birmingham hip resurfacing patients was 49.8 years (18 to 67), mean BMI was $25.7 \mathrm{~kg}$ / $\mathrm{m}^{2}$ (19.7 to 35.1 ) and mean activity 9.0 points (6 to 10 ).

The pre-operative pathology was predominantly osteoarthritis (Table I). All operations were performed using a posterior approach, which in the resurfacing group, was extensile. Thromboprophylaxis comprised the use of foot pumps and compression stockings and was identical for both groups. No hybrid THA patients had required further surgery following their index procedure before recruitment to the study. All patients were allowed full weightbearing immediately post-operatively. Birmingham hip resurfacing patients commenced impact activity at three months, but hybrid THA patients were advised to avoid heavy manual work and impact sports permanently.

Retrospective review. All patients were invited to attend outpatient clinics, where they completed a questionnaire recording complications of their hip arthroplasty, the Oxford hip score, ${ }^{19}$ the UCLA activity score, ${ }^{16}$ and the EuroQol quality of life score. ${ }^{20}$ The Oxford hip score is a validated patient-based outcome measure which is sensitive to clinically important changes and is scored from 12 (asymptomatic) to 60 (severe). The UCLA activity score was used with modifications for the British population. ${ }^{11}$ The EuroQol EQ-5D and EQ-visual analogue scores (EQVAS) are derived from a self-reported health status questionnaire and are valid and reliable in both population studies and other patient groups. ${ }^{21,22}$ Patients were also asked specifically about running, jogging, sporting activity and heavy manual work within the last four weeks. The medical notes were checked to ensure that no complications or reoperations had been missed. Anteroposterior (AP) and lateral radiographs were taken and compared with pre- and post-operative (24 hours, 3 months and at follow-up) radiographs (Table $\mathrm{II}$ ). Changes around the femoral and acetabular components of the hybrid hips were described on the AP radiographs using the zones of DeLee and Charnley $^{23}$ and Gruen, McNeice and Amstutz, ${ }^{24}$ and on the lateral radiographs according to Johnston et $\mathrm{al}^{25}$ for the femoral component and from zones IV to VI from anterior to posterior around the acetabular component. Linear

Table II. The radiographic variables examined

\begin{tabular}{|c|c|c|c|}
\hline Group & Radiograph & Variable & Site \\
\hline \multirow[t]{3}{*}{ Hybrid } & Follow-up & $\begin{array}{l}\text { Lucent lines (> } 1 \mathrm{~mm} \text { ) } \\
\text { Migration }\end{array}$ & Femoral and acetabular components \\
\hline & & Osteolysis & By zone \\
\hline & & Linear polyethylene wear & Femoral head/liner \\
\hline \multirow[t]{14}{*}{ Resurfacing } & Pre-operative & Neck-shaft angle & Femoral head and neck \\
\hline & & Femoral offset & \\
\hline & & Presence and size of femoral head cysts & \\
\hline & Post-operative & Seating & Acetabular component \\
\hline & & Abduction angle & \\
\hline & & Stem/shaft angle & Femoral component \\
\hline & & Femoral offset & \\
\hline & & Notching & \\
\hline & & Uncovered reamed bone & \\
\hline & & Stem tip position on lateral & \\
\hline & Follow-up & Lucent lines (> $1 \mathrm{~mm}$ ) & Femoral and acetabular components \\
\hline & & Migration & \\
\hline & & Osteolysis & By zone \\
\hline & & Change in density of trabeculation and cortical hypertrophy & Femoral neck \\
\hline
\end{tabular}


Table III. Linear polyethylene wear in the hybrid group

\begin{tabular}{llllll}
\hline Acetabular component & Number & $\begin{array}{l}\text { Mean follow-up } \\
\text { (mths) }\end{array}$ & $\begin{array}{l}\text { Incidence of } \\
\text { polyethylene wear (\%) }\end{array}$ & $\begin{array}{l}\text { Range } \\
\text { (mm) }\end{array}$ & $\begin{array}{l}\text { Mean linear wear } \\
\text { (all liners, mm/yr) }\end{array}$ \\
\hline Harris-Galante & 26 & 88.6 & $16(62)$ & 1 to 2.5 & 0.12 \\
Others & 25 & 70.6 & $13(52)$ & 0.5 to 1 & 0.07 \\
\hline
\end{tabular}

polyethylene wear was measured by the method of Dorr and Wan. ${ }^{26}$ Changes around the femoral component of the Birmingham hip resurfacings were described on the $\mathrm{AP}^{12}$ (zones 1 to 3 ) and lateral radiographs (assigned zones 4 to 6 from anterior to posterior). Changes around the acetabular component in the Birmingham hip resurfacings were assigned as for the hybrid hips. The surface arthroplasty risk index, ${ }^{27}$ a predictor of failure validated in 400 resurfacings, ${ }^{12}$ was calculated for each patient and correlated with the radiological findings.

The six Birmingham hip resurfacing patients who were unavailable for follow-up at the time of our first study ${ }^{15}$ completed the postal questionnaires but were not reviewed radiologically.

Approval for the study was obtained from the local research ethics committee.

Statistical analysis. The data were analysed by medical statisticians (MS, EW) using the STATA v8.0 package (StataCorp LP, College Station, Texas), using the Wilcoxon signed-rank test for comparison of Oxford hip and UCLA activity scores, the chi-squared test for comparison of participation in sports, running and heavy manual work, and the Mann-Whitney U test for EuroQol scores. The EQ-5D scores were adjusted for gender and age and were compared between groups. The EQ-VAS were compared directly between groups. A p value of $<0.05$ was considered to be significant.

\section{Results}

In the hybrid THA group, three patients had died but there was no other loss to follow-up. The medical records of these three patients revealed a satisfactory clinical performance at their latest review, giving $100 \%$ retrieval. There were, therefore, 51 hybrid THAs available for review. The mean follow-up was 80 months (42 to 120). In the Birmingham hip resurfacing group, one patient was lost to followup having emigrated. His medical records revealed satisfactory clinical and radiological results one year post-operatively, so 53 of the 54 hips were available for review (98\%). One patient refused further radiographic study. The mean follow-up was 61 months (52 to 71).

Functional outcome scores. There was no significant difference between the median Oxford hip score in the 51 hybrid THAs (14, mean $18.5 ; 12$ to 41 ) and the 53 Birmingham hip resurfacings $(13$, mean $15.9 ; 12$ to 42$)(p=0.139)$.

The Birmingham hip resurfacing patients had a significantly higher level of activity than those with hybrid THAs. The median UCLA activity score in the hybrid THA group was 7 (mean 6.8; 3 to 10) and in the Birmingham hip resur- facing group the median was 9 (mean 8.4; 4 to 10) (p $<$ 0.001).

The quality of life scores were better in the Birmingham hip resurfacing group. The mean EQ-5D score was 0.78 (0.06 to 1.00$)$ in the hybrid THA group and 0.9 (0.08 to $1.00)$ in the Birmingham hip resurfacing group $(\mathrm{p}=0.003)$. The mean EQ-VAS was 69.3 (15 to 100) in the hybrid THA group and 82.3 (20 to 100) in the Birmingham hip resurfacing group $(\mathrm{p}=0.001)$.

More patients with the Birmingham hip resurfacing ran, participated in sport and carried out heavy manual work than those with THA. During the four weeks before review, seven of $51(13.7 \%)$ hybrid THA patients and 31 of 53 $(58.5 \%)$ Birmingham hip resurfacing patients had run $(\mathrm{p}<$ 0.001), 17 (33.3\%) hybrid THA patients and 39 (73.6\%) Birmingham hip resurfacing patients participated in sport $(\mathrm{p}<0.001)$ and $20(39.2 \%)$ THA patients and $32(60.4 \%)$ Birmingham hip resurfacing patients performed heavy manual work $(\mathrm{p}=0.049)$.

The six Birmingham hip resurfacing patients who did not attend follow-up in our first study ${ }^{15}$ completed questionnaires. None had required further surgery. The median Oxford hip and UCLA scores were 12.5 and 8, respectively.

\section{Radiological outcomes}

Hybrid total hip arthroplasties (THAs). Of the hybrid THA group two patients $(4 \%)$ had lucent lines around the femoral component. In the first, these were in Gruen/Johnston zones 2, 3 and 8, and in the second 1, 4 and 8 . The mean stem subsidence was $2 \mathrm{~mm}$ (0 to 5$)$. There was no migration into varus or valgus.

A further four patients $(8 \%)$ had lucent lines around the acetabular component. These were in DeLee and Charnley zones I and IV, III and VI, III, and III and VI, respectively (zones as per DeLee and Charnley and additional three zones for the lateral radiograph). No components had migrated. Linear polyethylene wear occurred in 29 liners $(57 \%)$ (Table III). There was no significant difference in the incidence or rate of wear among the various component designs.

Osteolysis occurred in nine patients $(18 \%)$, six of whom had a Harris-Galante II (Zimmer), two an ABG II (Stryker Orthopaedics) and one a Zweymuller (PLUS Orthopaedics) component. All nine had polyethylene wear ranging from $0.5 \mathrm{~mm}$ to $2.5 \mathrm{~mm}$. Of the osteolytic areas, seven were femoral only, one acetabular (DeLee and Charnley zone II) and femoral, and one purely acetabular (DeLee and Charnley zone II). Femoral involvement was isolated to Gruen zone 7 in all patients except one, who also had involvement of 
Gruen zone 1. The mean age of the patients with osteolysis was 47 years (27 to 59) and mean follow-up was 83 months (46 to 108 ). Only three (33\%) of these patients had Oxford hip scores above 22 . Of the patients with osteolysis, three revisions have been planned and the remainder are under annual review. One further revision is planned in the hybrid group for recurrent dislocation.

Birmingham hip resurfacings. Pre-operatively, three patients had single femoral head cysts larger than $2 \mathrm{~cm}$ in diameter, nine had single cysts larger than $1 \mathrm{~cm}$ and four had two cysts larger than $1 \mathrm{~cm}$. Post-operatively, 19 acetabular com-

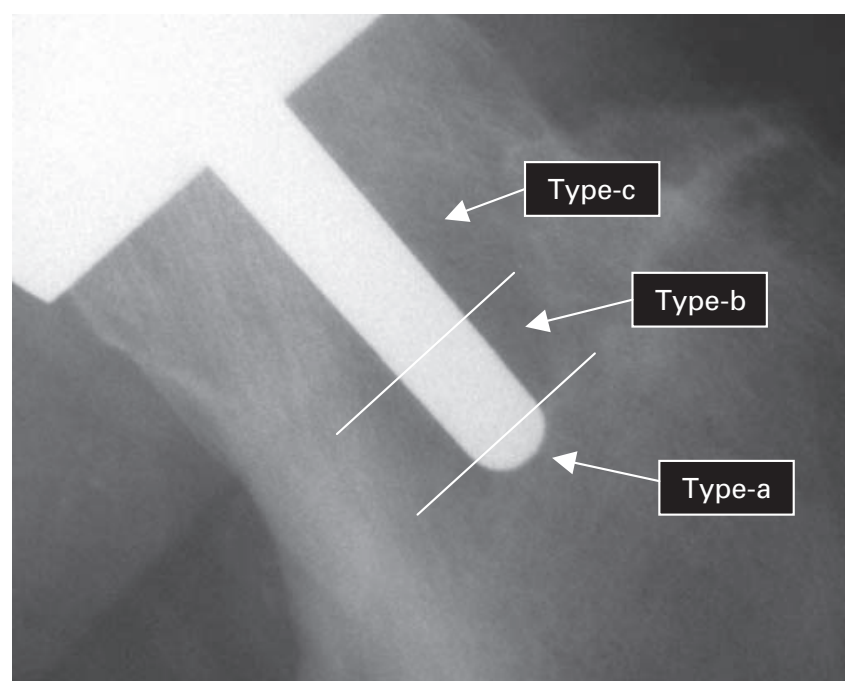

Fig. 1

The subclassification of pedestal signs into type-a, type-b, and type-c.

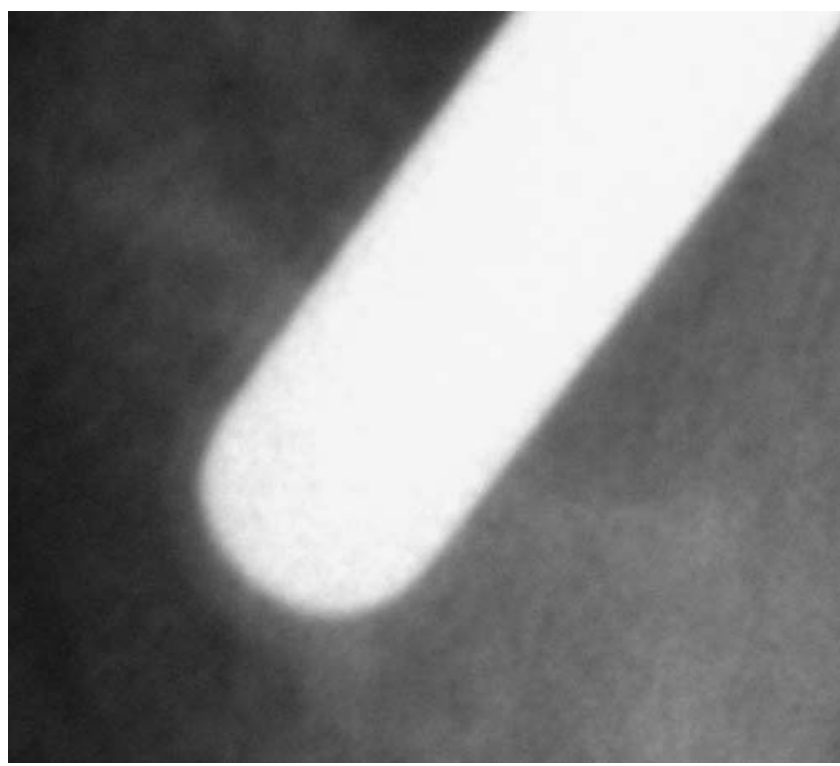

Fig. 3

Type-b pedestal sign.
Table IV. Our classification of radiological appearance of femoral component after metal-on-metal resurfacing

\begin{tabular}{cl}
\hline Classification & Radiological appearance \\
\hline Type & No change \\
0 & Pedestal sign but no migration \\
1 & Sclerotic line confined to curved tip of stem \\
a & Sclerotic line confined to distal $1 \mathrm{~cm}$ of shaft of stem \\
b & Sclerotic line \pm symmetrical lucent lines, extending \\
c & proximally beyond distal $1 \mathrm{~cm}$ of shaft \\
2 & Migration, usually into varus with asymmetrical lucent \\
3 & lines \\
\hline
\end{tabular}

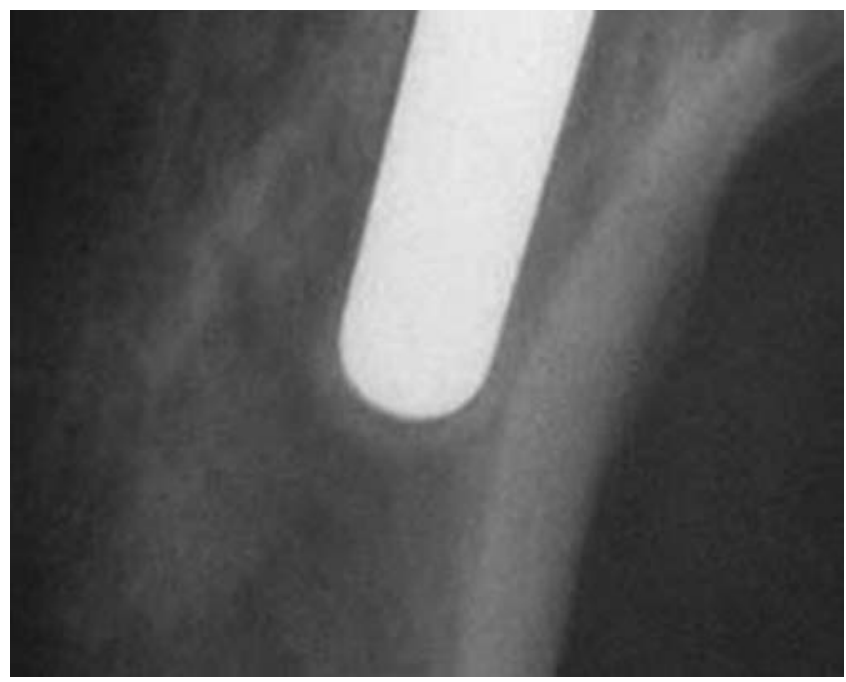

Fig. 2

Type-a pedestal sign.

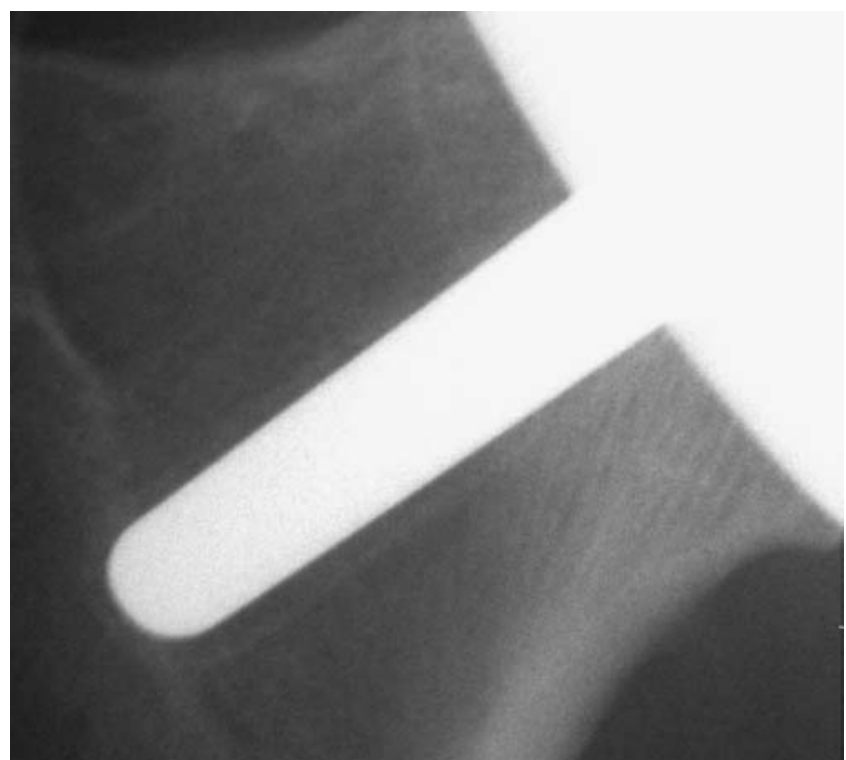

Fig. 4

Type-c pedestal sign 


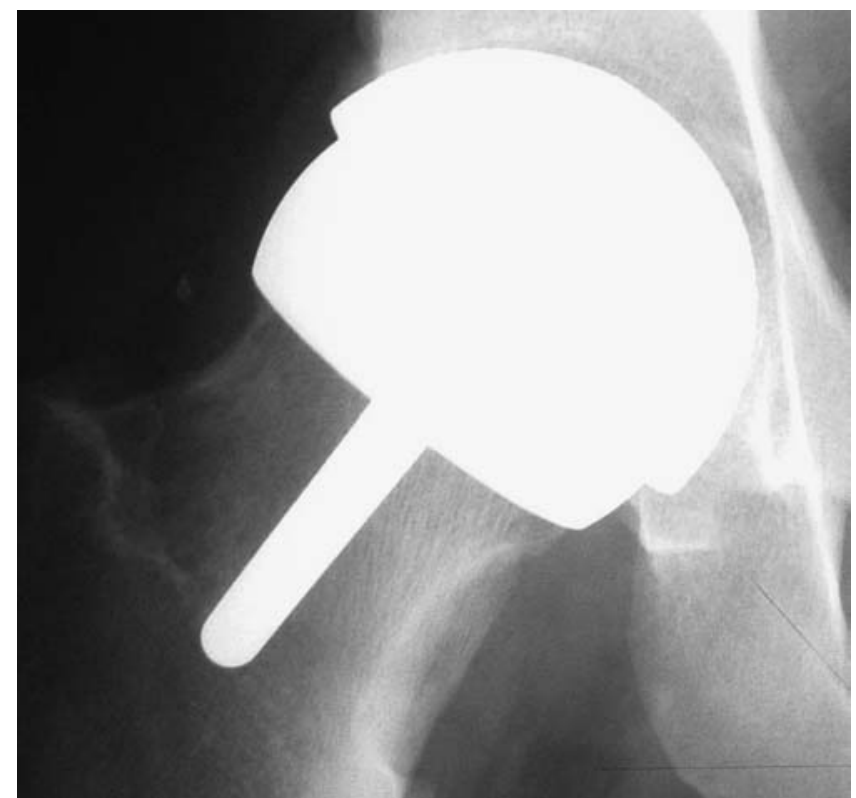

Fig. $5 a$

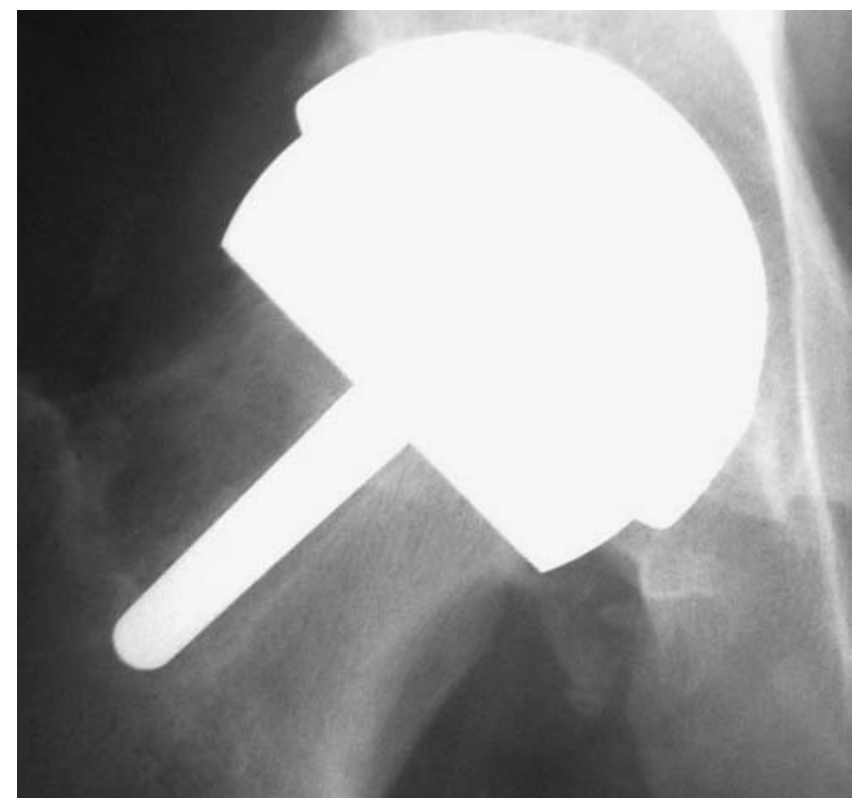

Fig. 5b

Migration of the femoral component; a) early post-operative radiograph of a 52-year-old man; b) at 60 months there was varus migration but an Oxford hip score of 14 and a UCLA score of 8.

ponents $(35 \%)$ were completely seated, and the mean abduction angle was $42^{\circ}\left(30^{\circ}\right.$ to $\left.56^{\circ}\right)$. The mean stem/shaft angle was $6.6^{\circ}$ valgus relative to the pre-operative neck/ shaft angle ( $7^{\circ}$ varus to $23^{\circ}$ valgus). Three hips were positioned in $5^{\circ}$ or more of relative varus. The stem position was in the central third on the lateral view in 48 hips (89\%) and in the anterior third in the remaining six $(11 \%)$. There was no significant change in femoral offset before or after surgery. Minor medial notches occurred in five patients, but laterally, there were none. Uncovered reamed bone was apparent on post-operative radiographs in ten hips (19\%); in five this was medial, two anterior, two lateral and one posterior. On follow-up radiographs all acetabular components were osseointegrated, with no migration or lucent lines.

Femoral component migration in Birmingham hip resurfacings (Table IV). A total of 16 femoral components $(31 \%)$ were unchanged from the post-operative radiographs (type- 0 ). A total of 31 femoral components $(60 \%)$ demonstrated a sclerotic line commencing at the tip of the stem and extending symmetrically towards the head for a variable distance (type-1, the 'pedestal sign', Figs 1 to 4). In some of these cases lucent lines were present, but these were symmetrical with no evidence of migration. We subdivided the pedestal signs into type- $1 \mathrm{a}$, type- $1 \mathrm{~b}$ and type$1 \mathrm{c}$ according to the progression of the sclerotic and lucent lines towards the head. Type- $1 \mathrm{a}$ (Fig. 2) was limited to the tip of the stem, type- $1 \mathrm{~b}$ (Fig. 3) commenced at the tip of the stem and extended $1 \mathrm{~cm}$ proximally, and type-1c (Fig. 4) extended more than $1 \mathrm{~cm}$. In five of 52 hips (10\%), femoral components with lucent lines had migrated (type-2), four into varus (Fig. 5) and one into slight valgus. In none of these patients was there clinical suspicion of infection, but in one the appearances suggested a malunited fracture (Fig. 6). All but one had satisfactory Oxford hip scores (12 to 18). One patient with an Oxford hip score of 40 had radiographic appearances suggestive of avascular necrosis (Fig. 7) and has now been revised. None of these five patients was notched, had uncovered reamed bone, was in varus, or was anteriorly or posteriorly malaligned on early postoperative radiographs. On pre-operative radiographs two of them had two cysts larger than $1 \mathrm{~cm}$ in diameter and one patient had a single cyst larger than $1 \mathrm{~cm}$. One 46-year-old man at 58 months follow-up, with an Oxford hip score of 12 and a UCLA activity score of 10 , had a $1 \mathrm{~cm}$ diameter area of osteolysis apparent on the lateral radiograph in zone 4 adjacent to the stem, but no other radiological changes. Both higher activity level $(\mathrm{r}=0.43, \mathrm{p}=0.002)$ and medial femoral neck remodelling (cortical hypertrophy and increased density of trabeculation (Fig. 8)) $(\mathrm{p}=0.013)$ appeared to be associated with increasing radiological change (Table V). The mean surface arthroplasty risk index was 2.56 ( 0 to 6 ) in the 52 resurfaced patients with follow-up radiographs available for study. A surface arthroplasty risk index greater than three occurred in eight patients who were thus categorised as 'high' risk. ${ }^{12}$ Three of the 'high'-risk patients $(37.5 \%)$ had type- $1 \mathrm{c}$ or type- 2 changes on their follow-up radiographs, compared with 11 of $44(25 \%)$ of 'low'-risk patients. The mean surface arthroplasty risk index of all patients with type- $1 \mathrm{c}$ or type- 2 


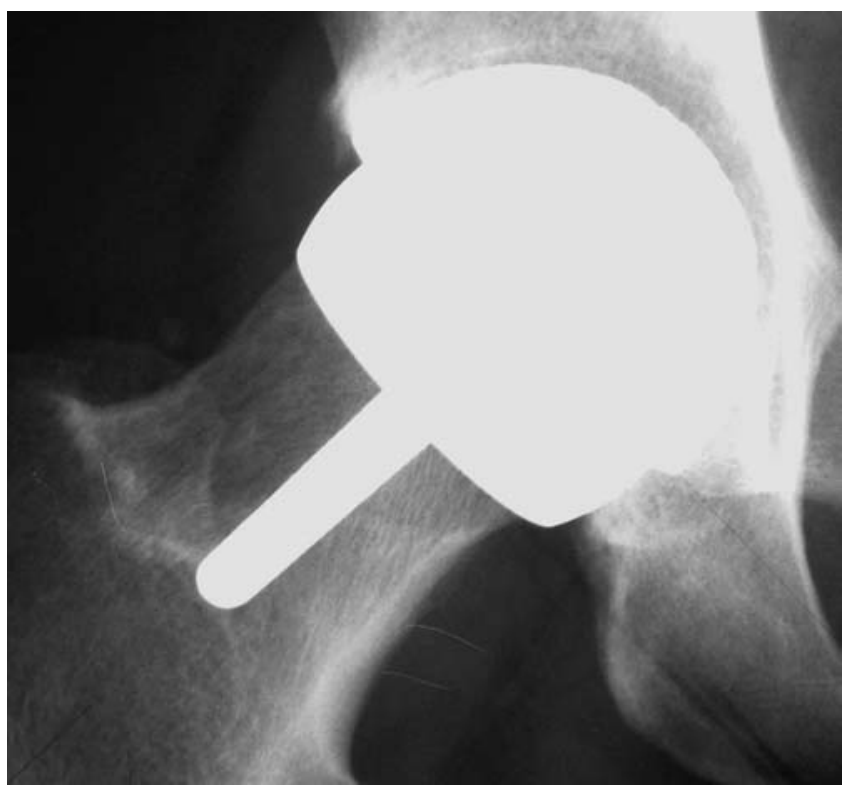

Fig. 6a

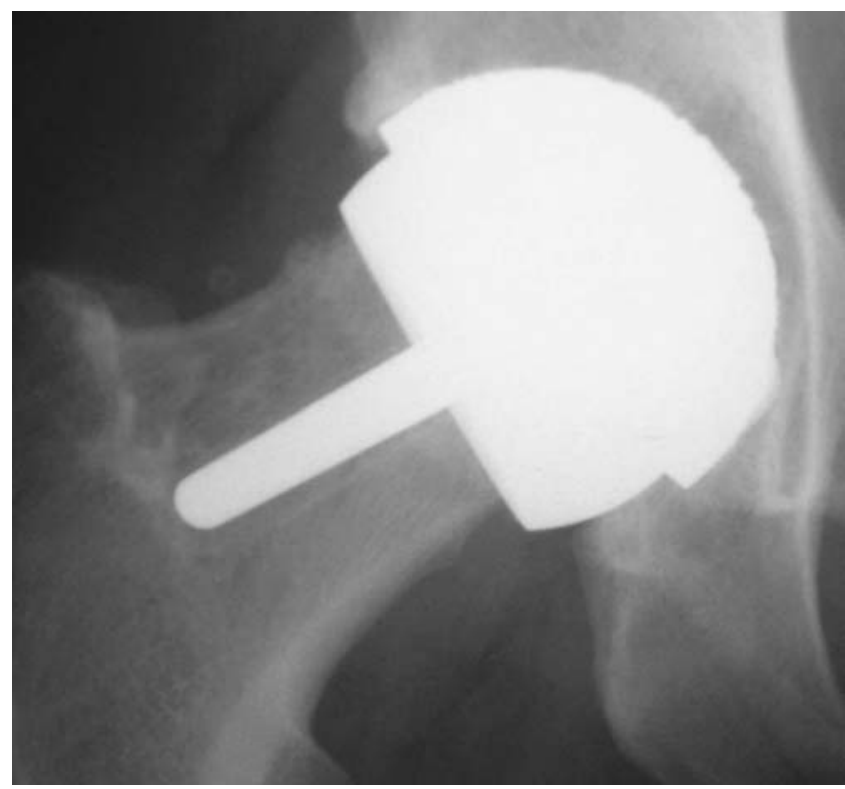

Fig. 6b

Migration of the femoral component, with appearances suggesting a malunited fracture; a) early post-operative radiograph of a 46-year-old man; b) at 65 months, varus migration and malunion but with an Oxford hip score of 12, and a University of California at Los Angeles score of 10.

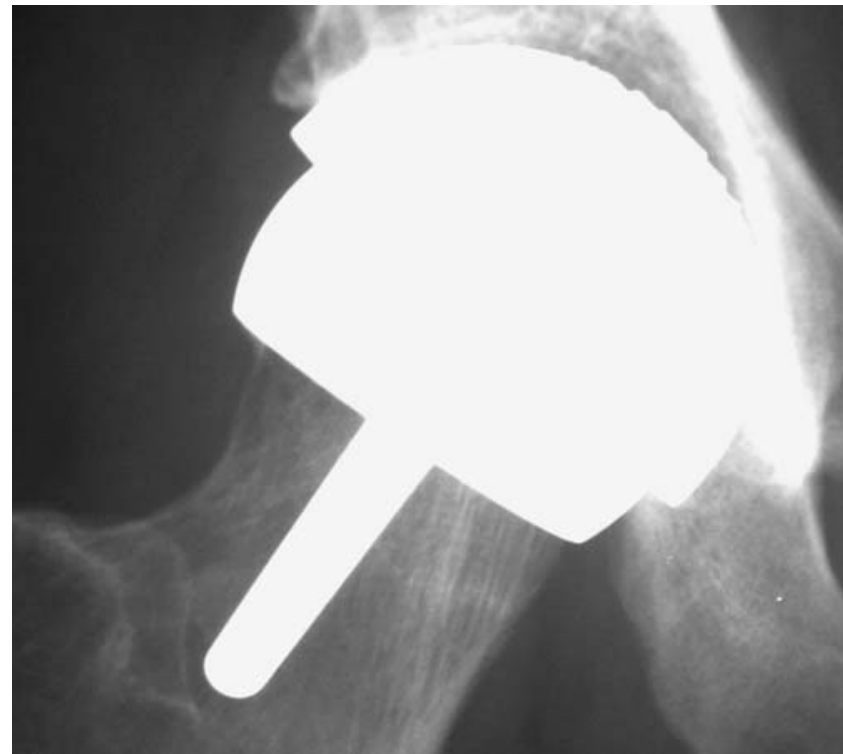

Fig. $7 a$

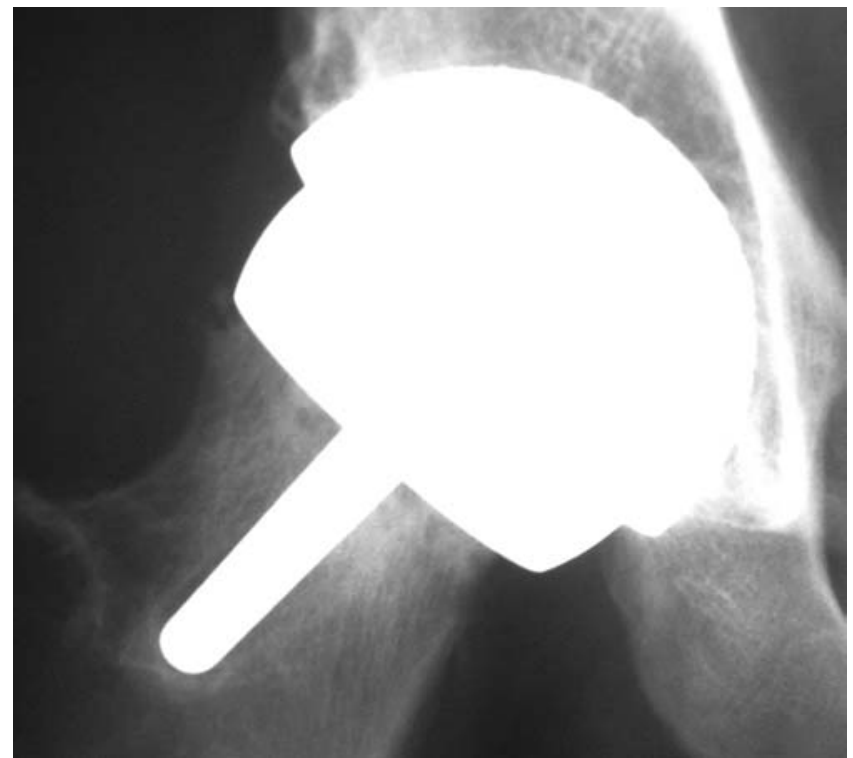

Fig. 7b

Migration of the femoral component with avascular necrosis; a) early post-operative radiograph of 44 -year-old man; b) at 60 months there was varus migration and avascular necrosis. The femoral component was probably loose, with an Oxford hip score of 40 and a University of California at Los Angeles score of 9 .

changes was 3.07 (1 to 5), compared with 2.37 (0 to 6) for the rest of the group.

Complications. In the hybrid THA group three patients dislocated once and one was a recurrent dislocator who is awaiting revision. There were three superficial wound infections, two deep-vein thromboses (DVT), one pulmon- ary embolism and one temporary sciatic nerve palsy. Two patients had trochanteric bursitis which was treated with steroid injections. In total, four of 51 hips ( $8 \%$ ) await revision, three for osteolysis and one for recurrent dislocation.

In the Birmingham hip resurfacing group there were no dislocations, two DVTs, one pulmonary embolism and one 


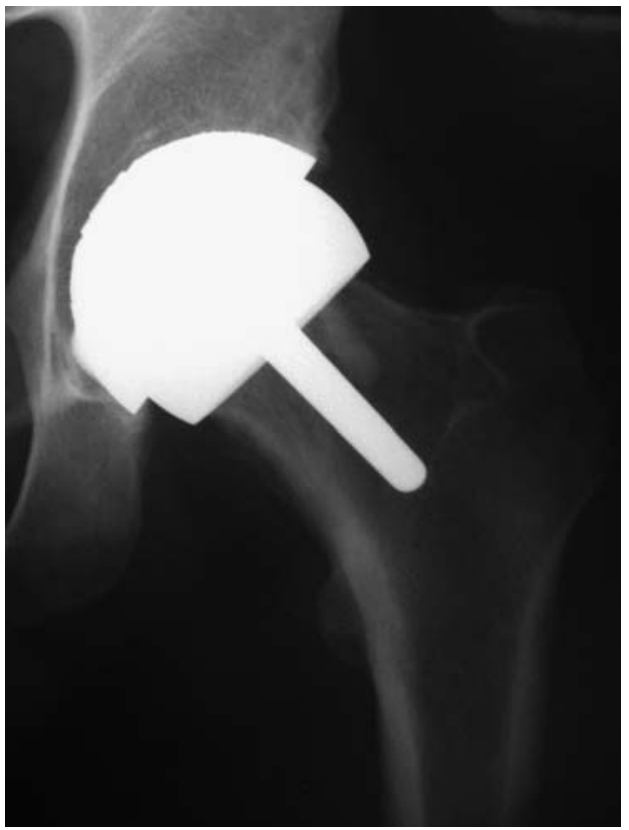

Fig. 8a

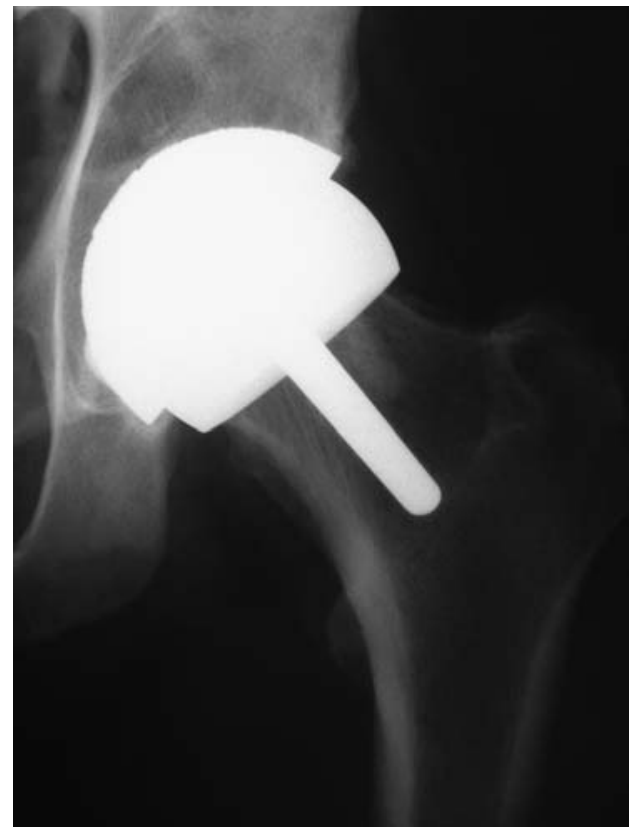

Fig. $8 b$

Remodelling of the femoral neck. Figure 8a demonstrates the post-operative radiograph; and b) the radiograph at 64 months showing an increased trabecular density.

Table V. Summary of radiological findings in the resurfacing group

\begin{tabular}{|c|c|c|c|c|c|c|c|c|}
\hline $\begin{array}{l}\text { Radiological } \\
\text { appearance }\end{array}$ & $\begin{array}{l}\text { Number of hips } \\
\text { (\% of } 52 \text { reviewed } \\
\text { in study) })^{*}\end{array}$ & $\begin{array}{l}\text { Mean age at } \\
\text { surgery } \\
\text { (yrs) }\end{array}$ & $\begin{array}{l}\text { Proportion of } \\
\text { males (\%) }\end{array}$ & $\begin{array}{l}\mathrm{BMI}^{\dagger} \\
\left(\mathrm{kg} / \mathrm{m}^{2}\right)\end{array}$ & $\begin{array}{l}\text { Mean follow-up } \\
\text { (mths) }\end{array}$ & $\begin{array}{l}\text { Mean Oxford } \\
\text { hip score }\end{array}$ & $\begin{array}{l}\text { Mean UCLA } \\
\text { score }\end{array}$ & $\begin{array}{l}\text { Incidence of } \\
\text { medical cortical } \\
\text { hypertrophy (\%) }\end{array}$ \\
\hline Type 0 & $16(30.8)$ & 50.3 & 56.3 & 25.6 & 63.8 & 16.6 & 7.6 & 18.8 \\
\hline Type 1a & $6(11.5)$ & 44.5 & 83.3 & 26.6 & 61.0 & 14.7 & 7.7 & 50.0 \\
\hline Type 1b & $16(30.8)$ & 47.8 & 81.3 & 26.0 & 59.3 & 14.1 & 9.0 & 50.0 \\
\hline Type 1c & $9(17.3)$ & 51.3 & 77.8 & 24.8 & 58.2 & 14.8 & 8.9 & 55.6 \\
\hline Type 2 & $5(9.6)$ & 51.0 & 100 & 26.5 & 61.6 & 19.6 & 9.2 & 80.0 \\
\hline Type 3 & $3(-)$ & 51.7 & 66.7 & 27.0 & - & - & - & - \\
\hline
\end{tabular}

* percentages are given for the 52 hips reviewed in the study. The three hips with type-3 appearance were not included in the calculation

$\dagger \mathrm{BMI}$, body mass index

¥ UCLA, University of California at Los Angeles

superficial wound infection. One patient had psoas impingement but declined surgical release. Of the 63 hips, four $(6 \%)$ have been revised for failure of the femoral component, two at six weeks, one at 12 months and one at 62 months. No hip in either group has required any other surgery.

Early fractures of the femoral neck. The first hip revised for an early fracture of the femoral neck within six weeks was in a 61-year-old man with osteoarthritis, whose femoral component had been placed in relative valgus of $5^{\circ}$; the femoral neck was notched and had uncovered reamed bone posterolaterally. The second hip was in a 57 -year-old man with a history of juvenile chronic arthritis with coxa vara and a bowed femur. Resurfacing was chosen rather than hybrid THA in order to eliminate the potential technical problem of inserting a stemmed femoral component. The
Birmingham hip resurfacing femoral component was placed in a central position with no notching or uncovered reamed bone, but because of the coxa vara it was not possible to position it in relative valgus. The third hip, in a $37-$ year-old woman with osteoarthritis, fractured secondary to avascular necrosis at one year after surgery. The femoral component had been placed in $2^{\circ}$ relative valgus with no notch or uncovered reamed bone.

\section{Discussion}

A review between 2000 and $2002^{28}$ concluded that there was "no clear consensus as to component choice or optimum fixation method in the younger patient". Of the acetabular components $74.2 \%$ were uncemented and resurfacing accounted for $18.8 \%$ of procedures. In $78 \%$ of cases, polyethylene was the acetabular-bearing surface. 
In our hybrid THAs the revision or intention-to-revise was $8 \%$ (four of 51 surviving hips) because of osteolysis secondary to polyethylene wear or recurrent dislocation. Of 63 original Birmingham hip resurfacings, four $(6 \%)$ were revised because of femoral component failure. Both groups also demonstrated impending failure on surrogate end-points. Of the 51 hybrid THAs, six $(12 \%)$ had lesser degrees of osteolysis, and revision to prevent further bone loss is anticipated. Of the 52 Birmingham hip resurfacings with radiographic, mid-term follow-up, four $(8 \%)$ demonstrated femoral component migration, which may fail by becoming painful or by resulting in a displaced fracture. Finally, changes were recorded in both groups, the significance of which is unknown. Polyethylene wear was recorded in a further $20(39 \%)$ hybrid THAs, a proportion of which will develop osteolysis. Pedestal signs were noted around $31(60 \%)$ of the Birmingham hip resurfacing femoral components and it is unknown how these will progress.

This study was retrospective, although the differences between THAs and Birmingham hip resurfacings were minimised by matching cases. All operations were performed by a single specialist hip surgeon using the same approach. The follow-up of the hybrid THAs was slightly longer than that of the Birmingham hip resurfacings.

The acetabular components of the hybrid THAs were heterogeneous, but there was no difference in the incidence or rate of wear between the different designs, suggesting that the weakness is in the polyethylene rather than in the component design. Wear rates were slightly higher in the Harris-Galante II (Zimmer) group, but their follow-up was longer. ${ }^{29}$ The Birmingham hip resurfacings were within the senior author's learning curve for the procedure, there may be a higher rate of technical error due to inexperience. This may have biased the rate of revision. ${ }^{12,30-32}$

The clinical results of the hybrid THAs are comparable with those of other medium-term reports in young patients. ${ }^{5,33-39}$ However, polyethylene wear and osteolysis are a cause for concern. This review confirmed our previous observation ${ }^{15}$ that a third of these patients refused to moderate activity likely to increase wear. Wear and osteolysis tend to be asymptomatic and increase with time, ${ }^{29,40}$ emphasising the need for regular long-term follow-up. The problems and degree of osteolysis represent the minimum that is truly present. ${ }^{41}$ Polyethylene preparation and storage have changed since this study ${ }^{42}$ and highly cross-linked polyethylene has now been introduced. This results in less wear debris ${ }^{43}$ but the release of biologically active particles may be proportionately higher, leading to similar overall osteolysis. ${ }^{44}$ As a result, we have stopped using polyethylene in young active patients and instead employ ceramicon-ceramic or metal-on-metal bearings.

The early results of metal-on-metal resurfacing have been encouraging. Early fractures are rare. Roentgen stereophotogrammetric analyses suggest that the femoral component is stable after two years. ${ }^{45,46}$ Excellent functional results have been reported. ${ }^{11-15}$ Our results, and those from Birmingham ${ }^{10}$ suggest that the early excellent clinical performance of the Birmingham hip resurfacing is maintained at five years in the majority of patients. However, neither the Birmingham ${ }^{10}$ nor the Australian ${ }^{13}$ series reported adverse radiological features. Amstutz et at, ${ }^{12}$ using the Conserve Plus (Wright Medical Technology, Arlington, Tennessee) prosthesis, noted radiolucent lines in over $25 \%$ of hips, in all three femoral component zones (our type- $1 \mathrm{~b}$ and type-c) in $2.9 \%$, and migration of femoral components (type-2) in 3.9\%. We suggest that these and the radiological signs we describe, represent avascular necrosis. Little et $\mathrm{al}^{31}$ noted loosening in only one of 13 retrieved specimens, but 12 demonstrated avascular necrosis. Late avascular necrosis leading to displaced fracture is a recognised and possibly inevitable complication of resurfacing. ${ }^{10-12,15,30,31}$

In our hips with pedestal signs or migration, there was increased density of femoral neck trabeculation and medical cortical hypertrophy. Remodelling on plain radiographs was also noted by Yishida et $\mathrm{al}^{47}$ who observed a mean increase in bone mineral density in Gruen zone 7 of $11 \%$ in a series of 13 Birmingham hip resurfacings. They did not, however, compare this with radiological changes around the stem.

If avascular necrosis is responsible for these radiological changes, the effect of the surgical approach used must be considered. The posterior approach is recommended for resurfacing, as it preserves abductor function and with a large head, dislocation is rare. However, it devascularises the femoral head, possibly permanently. ${ }^{48}$ Comparison with resurfacings performed through a transgluteal approach would clarify this concern.

We have compared two of the strategies used in the management of osteoarthritis in young active patients. Other options include ceramic-on-ceramic THA. ${ }^{49,50}$ Metal-onmetal bearings could be used with a stem, but a failed Birmingham hip resurfacing can easily be revised to this option and it would be sensible to reserve this for failed Birmingham hip resurfacings or femoral heads unsuitable for resurfacing. Regardless of the reservations detailed in this study, the results of hip arthroplasty in younger patients are better than those previously reported with cemented total hip replacement, ${ }^{51}$ in which there was a $14 \%$ revision rate after five years and $50 \%$ survival after 15 years. ${ }^{52}$ Longer followup may establish whether the change of practice recorded here represents a true advance.

The authors thank Michael Spratt and Elise Whitley, Medical Statisticians, North Bristol NHS Trust, for their help with the statistical analysis.

No benefits in any form have been received or will be received from a com mercial party related directly or indirectly to the subject of this article.

\section{References}

1. Chandler HP, Reineck FT, Wixson RL, McCarthy JC. Total hip replacement in patients younger than thirty years old: a five-year follow-up study. J Bone Joint Surg [Am] 1981;63-A:1426-34.

2. Dorr DL, Kane TJ 3rd, Conaty JP. Long-term results of cemented total hip arthroplasty in patients aged 45 years old or younger: a 16-year follow-up study. J Arthroplasty 1994:9:453-6. 
3. Joshi AB, Porter ML, Trail IA, et al. Long-term results of Charnley low-friction arthroplasty in young patients. J Bone Joint Surg [Br] 1993;75-B:616-23.

4. Boeree NR, Bannister GC. Cemented total hip arthroplasty in patients younger than 50 years of age: ten- to 18-year results. Clin Orthop 1993;287:153-9.

5. Callaghan JJ, Forest EE, Sporer SM, Goetz DD, Johnston RC. Total hip arthroplasty in the young adult. Clin Orthop 1997;344:257-62.

6. Harris WH. Hybrid total hip replacement: rationale and intermediate clinical results. Clin Orthop 1996;333:155-64.

7. Maloney WJ, Galante J0, Anderson M, et al. Acetabular fixation in primary total hip arthroplasty: fixation, polyethylene wear, and pelvic osteolysis in primary total hip replacement. Clin Orthop 1999;369:157-64.

8. Amstutz HC, Grigoris P, Dorey FJ. Evolution and future of surface replacement of the hip. J Orthop Sci 1998;3:169-86.

9. McMinn D, Treacy R, Lin K, Pynsent P. Metal-on-metal surface replacement of the hip: experience of the McMinn prosthesis. Clin Orthop 1996;329 (Suppl):89-98.

10. Treacy RBC, McBryde CW, Pynsent PB. Birmingham hip resurfacing arthroplasty: a minimum follow-up of five years. J Bone Joint Surg [Br] 2005;87-B:167-70.

11. Daniel J, Pynsent PB, McMinn DJW. Metal-on-metal resurfacing of the hip in patients under the age of 55 years with osteoarthritis. J Bone Joint Surg [Br] 2004; 86-B:177-84.

12. Amstutz HC, Beaulé PE, Dorey FJ, et al. Metal-on-metal hybrid surface arthroplasty: two to six-year follow-up study. J Bone Joint Surg [Am] 2004;86-A:28-39.

13. Back DL, Dalziel R, Young D, Shimmin A. Early results of primary Birmingham hip resurfacings: an independent prospective study of the first 230 hips. J Bone Joint Surg [Br] 2005;87-B:324-9.

14. DeSmet KA, Pattyn C, Verdonk R. Early results of primary Birmingham hip resurfacing using a hybrid metal-on-metal couple. Hip 2002;12:158-62.

15. Pollard TCB, Basu C, Ainsworth R, Lai W, Bannister GC. Is the Birmingham hip resurfacing worthwhile? Hip 2003;13:25-8.

16. Amstutz HC, Thomas BJ, Jinnah R, et al. Treatment of primary osteoarthritis of the hip: a comparison of total joint and surface replacement arthroplasty. J Bone Joint Surg [Am] 1984;66-A:228-41.

17. Shepherd EF, Toloza E, McClung CD, Schmalzried TP. Step activity monitor: increased accuracy in quantifying ambulatory activity. J Orthop Res 1999;17:703-8.

18. Zahiri C, Schmalzried TP, Szuszcewicz ES, Amstutz HC. Assessing activity in joint replacement patients. J Arthroplasty 1998;12:890-5.

19. Dawson J, Fitzpatrick R, Carr AJ, Murray D. Questionnaire on the perceptions of patients about total hip replacement. J Bone Joint Surg [Br] 1996;78-B:185-90.

20. Brooks R. EuroOol: the current state of play. Health Policy 1996;37:53-72

21. Kind $\mathbf{P}$, Gudex $\mathbf{C M}$. Measuring health status in the community: a comparison of methods. J Epidemiol Community Health 1994;48:86-91.

22. Brazier J, Jones N, Kind P. Testing the validity of the EuroOol and comparing it with the SF-36 health survey questionnaire. Qual Life Res 1993;2:169-80.

23. DeLee JG, Charnley J. Radiological demarcation of cemented sockets in total hip replacement. Clin Orthop 1976;121:20-32.

24. Gruen TA, McNeice GM, Amstutz HC. "Modes of failure" of cemented stem-type femoral components: a radiographic analysis of loosening. Clin Orthop 1979;141: $17-27$.

25. Johnston RC, Fitzgerald RH Jr, Harris WH, et al. Clinical and radiographic evaluation of total hip replacement: a standard system of terminology for reporting results. J Bone Joint Surg [Am] 1990;72-A:161-8.

26. Dorr LD, Wan Z. Comparative results of a distal modular sleeve, circumferential coating, and stiffness relief using the anatomic porous replacement II. J Arthroplasty 1996:11:419-28.

27. Beaulé PE, Dorey FJ, LeDuff M, Gruen T, Amstutz HC. Risk factors affecting outcome of metal-on-metal surface arthroplasty of the hip. Clin Orthop 2004;418:87-93.

28. Mundy GM, Esler CNA, Harper WM. Primary hip replacement in young osteoarthritic patients: current practices in one UK region. Hip 2005;15:159-65.
29. Devane PA, Horne JG, Martin K, Coldham G, Krause B. Three-dimensional wear of a press-fit titanium prosthesis: factors influencing generation of polyethylene debris. J Arthroplasty 1997;12:256-66.

30. Shimmin AJ, Back D. Femoral neck fractures following Birmingham hip resurfacing: a national review of fifty cases. J Bone Joint Surg [Br] 2005;87-B:463-4.

31. Little CP, Ruiz AL, Harding IJ, et al. Osteonecrosis in retrieved femoral heads after failed resurfacing arthroplasty of the hip. J Bone Joint Surg [Br] 2005;87-B:320-3.

32. Amstutz HC, Campbell PA, Le Duff MJ. Fracture of the neck of the femur after surface arthroplasty of the hip. J Bone Joint Surg [Am] 2004;86-A:1874-7.

33. Kim YH, Kook HK, Kim JS. Total hip replacement with a cementless acetabular component and a cemented femoral component in patients younger than fifty years of age. J Bone Joint Surg [Am] 2002;84-A:770-4.

34. Crowther JD, Lachiewicz PF. Survival and polyethylene wear of porous-coated acetabular components in patients less than fifty years old: results at nine to fourteen years. J Bone Joint Surg [Am]2002;84-A:729-35.

35. Berger RA, Jacobs JJ, Quigley LR, Rosenberg AG, Galante J0. Primary cementless acetabular reconstruction in patients younger than 50 years: 7 - to 11-year results. Clin Orthop 1997;344:216-26

36. Sporer SM, Callaghan JJ, Olejniczak JP, Goetz DD, Johnstone RC. Hybrid total hip arthroplasty in patients under the age of fifty: a five- to ten-year follow-up. J Arthroplasty 1998;13:485-91.

37. Dunkley AB, Eldridge JDJ, Lee MB, Smith EJ, Learmonth ID. Cementless acetabular replacement in the young: a 5- to 10-year prospective study. Clin Orthop 2000;376:149-55.

38. Tompkins GS, Jacobs JJ, Kull LR, Rosenberg AG, Galante JO. Primary total hip arthroplasty with a porous-coated acetabular component: seven- to ten-year results. J Bone Joint Surg [Am] 1997;79-A:169-76

39. Lewallen DG, Cabanela ME. Hybrid primary total hip arthroplasty: a 5- to 9-year follow-up study. Clin Orthop 1996;333:126-33.

40. Della Valle CJ, Berger RA, Shott S, et al. Primary total hip arthroplasty with a porous-coated acetabular component: a concise follow-up of a previous report. J Bone Joint Surg [Am] 2004;86-A:1217-22.

41. Gaffey JL, Callaghan JJ, Pedersen DR, et al. Cementless acetabular fixation at fifteen years: a comparison with the same surgeon's results following acetabular fixation with cement. J Bone Joint Surg [Am]2004;86-A:257-61.

42. Ingham E, Fisher J, Stone MH. Wear of historical polyethylenes in hip prostheses: biomechanical success and a biological failure. Hip 2003;13(Suppl 2):17-27.

43. Digas G, Karrholm J, Thanner J, Malchau H, Herberts P. Highly cross-linked polyethylene in total hip arthroplasty. Clin Orthop 2004;429:6-16.

44. Fisher J, Ingham E, Stone $\mathbf{M H}$. Alternative bearing couples in total hip replacements: solutions for young patients. Hip 2003;13(Suppl 2):31-5.

45. Glyn-Jones S, Gill HS, McLardy-Smith P, Murray DW. Roentgen sterephotogrammetric analysis of the Birmingham hip resurfacing arthroplasty: a two-year study. J Bone Joint Surg [Br] 2004;86-B:172-6.

46. Itayem R, Arndt A, Nistor L, McMinn D, Lundberg A. Stability of the Birmingham hip resurfacing at two years: a radiostereophotogrammetric analysis study. J Bone Joint Surg [Br] 2005;87-B:158-62.

47. Yishida Y, Sugano N, Nishii T, et al. Preservation of the bone mineral density of the femur after surface replacement of the hip. J Bone Joint Surg [Br] 2004;86-B:185-9.

48. Steffen RT, Smith SR, Urban JPG, et al. The effect of hip resurfacing on oxygen concentration in the femoral head. J Bone Joint Surg [Br] 2005;87-B:1468-74.

49. Bizot P, Hannouche D, Nizard R, Witvoet J, Sedel L. Hybrid alumina total hip arthroplasty using a press-fit metal backed socket in patients younger than 55 years: a six- to 11-year evaluation. J Bone Joint Surg [Br] 2004;86-B:190-4.

50. Nizard R, Sedel L, Hannouche D, Hamadouche M, Bizot P. Alumina pairing in total hip replacement. J Bone Joint Surg [Br] 2005;87-B:755-8.

51. White SH. The fate of the cemented total hip arthroplasty in young patients. Clin Orthop 1988;231:29-34

52. Langdon I, Bannister GC. Cemented hip replacement in patients younger than 50 years: 16-24 year results. Hip 1998;9:151-3. 